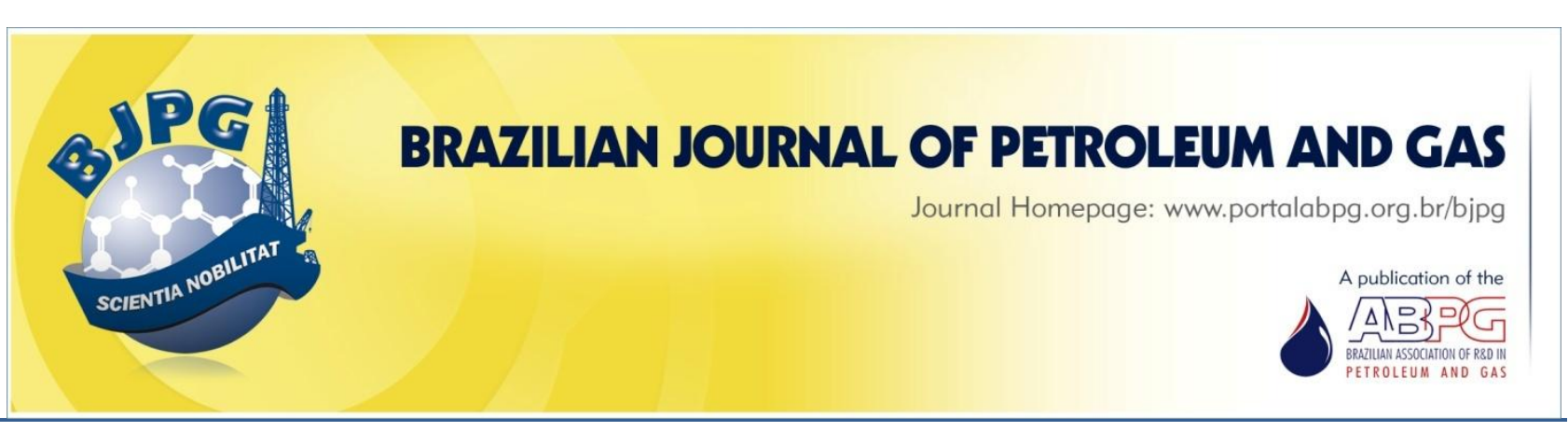

\title{
COST OPTIMIZATION OF NEUTRALIZING AMINES USED IN DISTILLATION COLUMN OVERHEAD SYSTEMS
}

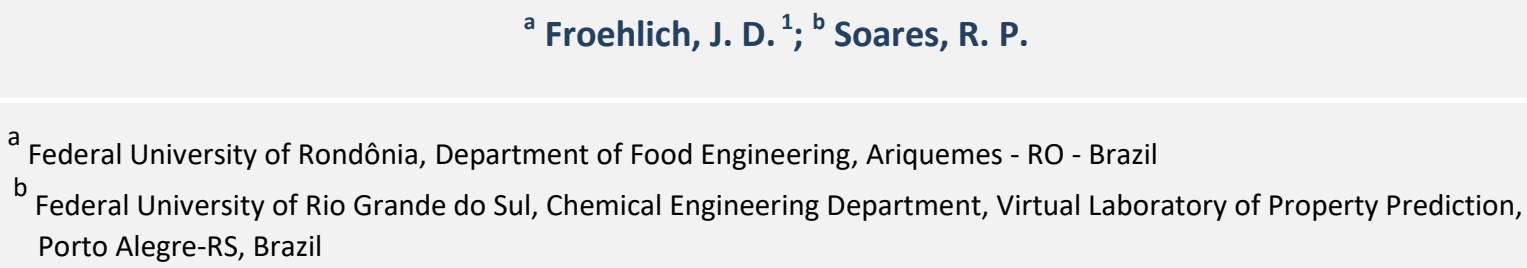

Received: 16.10.2018 / Revised: 25.11.2018 / Accepted: 10.04.2019 / Published on line: 18.06.2019

\begin{abstract}
Crude distillation equipment is usually subject to the corrosive activity of acids. This problem could be mitigated by the addition of amines to reduce corrosion effects. The present work applies two different optimization methods, Nelder-Mead (NM) and Particle Swarm Optimization (PSO), to reduce operational costs by adding neutralizing amines. This improvement was accomplished using an in-house software taking into account the following parameters: salt formation temperature, water dew point temperature, and $\mathrm{pH}$ in condensate vessel conditions. These operating parameters and the addition of amines were used to minimize the cost in four different case studies. Results show that a considerable cost reduction is possible in several cases when using the global optimization method. Nevertheless, the local search method was less successful in improving the given start point, getting stuck in local minima.
\end{abstract}

\section{KEYWORDS}

crude oil; distillation; amines; optimization; corrosion

\footnotetext{
${ }^{1}$ To whom all correspondence should be addressed. Address: Federal University of Rondônia, Department of Food Engineering, Tancredo Neves Ave., n. 3450, Ariquemes-RO, Brazil. Zip code: 76872-862 | Phone number+55 (69) 3535-3563 / +55 (51) 3308-2852 | e-mail: josiel.dimas@unir.br, rafael@enq.ufrgs.br doi:10.5419/bjpg2019-0007
} 


\section{INTRODUCTION}

The process of refining crude oil through distillation is very important in the production of various oil-based components and products. These products are used widely in our daily lives; among them are gasoline, kerosene, and diesel. Heavier fractions, which have a higher boiling point, are collected in the tower bottoms, while lighter fractions, which present lower boiling point, are recovered from the overhead fraction (Fearnside \& Murphy, 1995).

Typically, the first approach to reduce corrosion on the overhead section is to promote oil desalting with water (Fearnside \& Murphy 1998). However, no matter what type of petroleum feedstock is used, it is usually impractical to remove the salts completely (Branden et al., 1999). These salts hydrolyze in the pre-heat stage and the distillation equipment ends up subjected to the corrosive activity of acids such as $\mathrm{H}_{2} \mathrm{~S}, \mathrm{HCl}, \mathrm{H}_{2} \mathrm{CO}_{3}$ and organic acids, as water condenses in the overhead section (Branden et al., 1999).

Furthermore, steam is added to the bottom of the tower to promote stripping of light compounds from the bottom. Water can also be added to the top of the column to wash salts away. The amount of water added to the system is usually substantial, making the top stream reach values of $40 \%$ (molar basis) in water. All water is condensed in the overhead exchangers and is temporarily accumulated in the condensate drum (Branden et al., 1999). Because of the water temperature is close to its dew point, the temperature variation that occurs during the phase change of the condensing mixture increases the chance of a corrosive attack by acid species. Other possibility of corrosive attack may occur when acidic species react further in the gas phase with ammonia/amines (e.g. $\mathrm{NH}_{3}$ ) and salt formation occurs (e.g. $\mathrm{NH}_{4} \mathrm{Cl}$ ). Depending on operating conditions, salts may form at a temperature higher than the water dew temperature. When these salts precipitate, they may form a deposit on the internal surface of the equipment, triggering corrosion processes, and, in turn, causing great damages to the equipment and considerable financial losses (Lehrer \& Edmondson, 1993).

The top systems of distillation towers are also called OVHD - Overhead Gutzeit (2006). Differently from the amine injection method presented by Branden et al. (1999), Gutzeit (2006) suggests the addition of amines and inhibitors to the top of the towers along with the washing water, according to Figure 1.

Neutralizing amines are considered weak bases when applied to tower systems. They play a key role in the corrosion inhibition as they can neutralize the acidic species present. This increases the $\mathrm{pH}$ value making the mixture less acidic in top systems. To minimize the corrosion in the system, the $\mathrm{pH}$ range should be about 5 to 6.5 (Branden et al., 1999; Gutzeit, 2006).

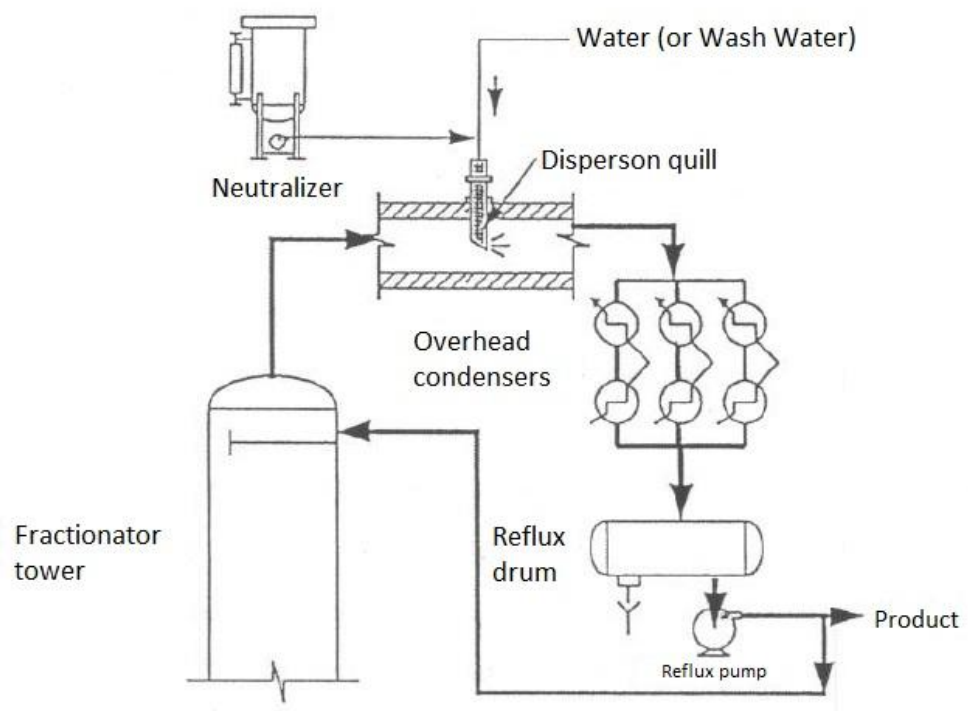

Figure 1. Schematic representation of the OVHD system investigated in this work Cases. adapted from (Gutzeit, 2006). 
The main goal of adding amines to the process is to promote the neutralization of acidic species. The inhibitors, on the other hand, form a protective film between the internal surface of the equipment and the mixture of the medium, through chemical adsorption or electrostatic forces, protecting them from corrosive attacks (Neves, 2009).

In the OVHD system of distillation processes, there are three main operational parameters to consider: salt formation temperature, water dew point temperature, and $\mathrm{pH}$ in the condensate vessel. The salts formed by precipitation generally are detected during the distillation of crude oil at the beginning of the first stage of condensation. At the lower levels of the fractionating column (high temperatures), sulfur compounds can be decomposed to form salts such as ammonium hydrosulfide $\left(\mathrm{NH}_{4} \mathrm{HS}\right)$ and nitrogen compound. These compounds might react with hydrochloric acid to form salts like ammonium chloride $\left(\mathrm{NH}_{4} \mathrm{Cl}\right)$. The formation of these salts depend on the equilibrium constants and the partial pressures of the components in mixture (McLaughlin and $\mathrm{Wu}$, 1997).

Water dew point temperature is obtained assuming that the water will condensate practically pure, considering only gases dissolved in small amounts or slightly miscible oils. Water dew point temperature can be calculated through its total and partial pressures relative to its saturation pressure, applying the modified Raoult's law and the Antoine equation, respectively (Koretsky, 2012).

The $\mathrm{pH}$ of the top vessel, as well as the $\mathrm{pH}$ of the water, can be determined by the dissociation of water and acidic species and their respective equilibrium constants along with material balances.

The process of adding neutralizing amines to accomplish corrosion control represent an operating cost. In this work, with the objective of reducing the costs associated with the corrosion control by amine addition, two optimization methods were used: a local search method (Nelder-Mead simplex) and a global search method (Particle Swarm Optimization - PSO). These methods were implemented in an in-house software developed by our group.

\section{METHODOLOGY}

\subsection{Operational parameter calculations}

An adequate $\mathrm{pH}$ of the aqueous phase is crucial to reduce corrosion effects. In this work, the $\mathrm{pH}$ of the aqueous phase in the distillate vessel is used as an operational parameter. Two other parameters are also considered: the water dew point temperature and salt formation temperature.

The prediction of these operational parameters were implemented in an in-house software developed by our group. Besides interactions with ammonia $\left(\mathrm{NH}_{3}\right)$, the implementation also supports its mixture with the following amines: 3Methoxypropylamine (MOPA), Monoethanolamine (MEA), N-Methylmorpholine (NMM), Trimethylamine (TMA), Ethylenediamine (EDA), and Pyridine (PYRID). Along with the computation of the operational parameters, given the cost of each amine, the software can also compute the current operational cost for the current selected neutralizing mixture. Finally, given the operational conditions, the code can optimize the composition of the neutralizing mixture to achieve an optimal (minimum) operating cost.

During the optimization step, the following constraints need to be applied: the $\mathrm{pH}$ in condensate vessel should be higher than 6.5 and salt formation temperature should be lower than the water dew point temperature.

\subsubsection{Water dew point temperature}

Assuming that the aqueous phase is practically pure water, the water dew point temperature can be calculated by its partial pressure relative to its saturation pressure (McLaughlin and Wu, 1997). Starting from the modified Raoult's law:

$P y_{i}=x_{i} \gamma_{i} P_{i}^{s a t}(T)$

Where:

$P=$ pressure of system;

$y_{i}=$ the molar fractions in vapor phases;

$x_{i}=$ the molar fractions in liquid phases;

$\gamma_{i}=$ the activity coefficient of the species $\mathrm{i}$;

$P_{i}^{s a t}=$ the saturation pressure of compound $i$. 
Furthermore, the aqueous liquid phase (if present) is assumed to be pure water. Thus, the product $x_{i} \gamma_{i}$ reduces to 1 , simply resulting in:

$P_{\mathrm{H}_{2} \mathrm{O}}^{s a t}(T)=y_{\mathrm{H}_{2} \mathrm{O}} P$

Where:

$P_{\mathrm{H}_{2} \mathrm{O}}^{\mathrm{sat}}=$ saturation pressure of water;

$y_{\mathrm{H}_{2} \mathrm{O}}=$ molar fractions in vapor of water;

$P=$ pressure of system .

Thus, the temperature dew point of water can be calculated for given operational conditions ( $P$ and $y_{\mathrm{H}_{2} \mathrm{O}}$ ) using a temperature dependent correlation for $P_{\mathrm{H}_{2} \mathrm{O}}^{\mathrm{Sat}}$. In this work, the Antoine equation was used:

$\ln \left(P^{s a t}[\right.$ bar $\left.]\right)=A-\frac{B}{T+C}$

Where:

$P^{\text {sat }}=P_{\mathrm{H}_{2} \mathrm{O}}^{\text {sat }}$ : saturation pressure of water;

$A, B, C=$ empirical constants of Antoine equation for water;

$T=T_{\mathrm{H}_{2} \mathrm{O}}=$ water dew point temperature.

\subsubsection{Salt formation temperature}

The amines could form hydrochloride salts. The salt formation temperature will be exemplified in this section using ammonium hydrochloride, as follows:

$\mathrm{NH}_{4} \mathrm{Cl}_{(s)} \leftrightarrow \mathrm{NH}_{3(g)}+\mathrm{HCl}_{(g)}$

Assuming solid-vapor equilibrium, that the solid phase is pure, and that vapor phase is an ideal gas (low pressures), the equilibrium constants can be related to the partial pressures by:

$K_{1}(T)=P_{\mathrm{NH}_{3}} P_{\mathrm{HCl}}$

Where:

$K_{1}=$ equilibrium constant for salt $1\left(\mathrm{NH}_{4} \mathrm{Cl}\right)$;

$T$ = temperature;

$P_{\mathrm{NH}_{3}}=P y_{\mathrm{NH}_{3}}=$ partial pressures of $\mathrm{NH}_{3}$;
$P_{H C l}=P y_{H C l}=$ partial pressures of $\mathrm{HCl}$.

Equation 4 allows one to represent the equilibrium constants through the molar fractions and total system pressure (McLaughlin \& $\mathbf{W u}$ 1997):

$K_{1}(T)=P^{2} y_{N H_{3}} y_{H C l}$

Where:

$P=$ operating pressure;

$y_{\mathrm{NH}_{3}}=$ molar fractions of $\mathrm{NH}_{3}$;

$y_{\mathrm{HCl}}=$ molar fractions of $\mathrm{HCl}$.

Equilibrium constant $K_{1}$ can be obtained based on pure salt sublimation pressure data. When the pure salt sublimates, vapor is an equimolar mixture of $\mathrm{NH}_{3}$ and $\mathrm{HCl}$ with $y_{\mathrm{NH}_{3}}=y_{\mathrm{HCl}}=0.5$. Thus, Equation 5 reduces simply to:

$K_{1}(T)=0.25 P_{\text {subl }}^{2}$

Where:

$P_{\text {subl }}=$ sublimation pressure of the salt.

Where $P_{\text {subl }}$ is a function of temperature only. The equilibrium constant determined by Equation 6 can also be translated into the Gibbs free energy of reaction as follows:

$\ln K_{1}(T)=-\frac{\Delta g_{r x n}^{\circ}}{R T}$

Where:

$\Delta g_{r x n}^{\circ}=$ Gibbs free energy of reaction;

$R=$ ideal gas constant

Furthermore, assuming that the enthalpy of reaction (or sublimation) is constant, the following equation can be used to extrapolate the constant for different temperatures:

$\ln K_{1}\left(T_{2}\right)=\ln K_{1}\left(T_{1}\right)-\frac{\Delta h_{r x n}^{\circ}}{R}\left(\frac{1}{T_{2}}-\frac{1}{T_{1}}\right)$

Where:

$\Delta h_{r x n}^{\circ}=$ reaction enthalpy of formation;

$T_{1}=$ reference salt temperature;

$T_{2}=$ salt temperature to be determined. 
Table 1. Salt formation equilibrium constants as well as pKa data for ammonia and amines.

\begin{tabular}{lllll}
\hline Amine Salt & $\begin{array}{l}P_{\text {subl }} \\
(\mathrm{Pa})\end{array}$ & $\begin{array}{l}\Delta g_{\text {rxn }}^{\circ} \\
(\mathrm{kJ} / \mathrm{mol})\end{array}$ & $\begin{array}{c}\text { Ref.Temp } \\
(\mathrm{K})\end{array}$ & pKa \\
\hline $\mathrm{NH}_{3}-\mathrm{HCl}$ & $0.0021[1]$ & 91.420 & 298.15 & $9.21[6]$ \\
$\mathrm{MOPA}-\mathrm{HCl}$ & $1.0700[2]$ & 75.192 & 372.04 & $10.3[7]$ \\
$\mathrm{MEA}-\mathrm{HCl}$ & $1.0700[2]$ & 75.192 & 372.04 & $9.44[8]$ \\
$\mathrm{NMM}-\mathrm{HCl}$ & $0.9380[3]$ & 77.041 & 377.59 & $7.14[5]$ \\
$\mathrm{TMA}-\mathrm{HCl}$ & $70.000[4]$ & 52.930 & 400.00 & $9.76[6]$ \\
EDA $-\mathrm{HCl}$ & $0.0038[5]$ & 176.620 & 380.37 & $10.7[5]$ \\
PYRID - HCl & $45.600[5]$ & 52.657 & 377.59 & $5.25[5]$ \\
\hline
\end{tabular}

[1](Callanan and Smith, 1971), [2](Fearnside and Murphy, 1998), [3](Lehrer and Edmondson, 1993) [4](Belusso et al., 2017), [5](Lehrer and Edmondson, 1993), [6](Hall, 1957), [7](Brown et al., 1971), [8](Hamborg \& Versteeg 2009)

Therefore, by using $P_{\text {subl }}$ data of the amine salts, it is possible to determine $\Delta g_{r x n}^{\circ}$ and $\Delta h_{r x n}^{\circ}$. To obtain $\Delta h_{r x n}^{\circ}$, sublimation pressure data, at least two different temperatures are needed. For some amines, data for only one temperature is available in the literature, making it impossible to determine the sublimation enthalpy value. However, these enthalpy data are usually very similar for different amines, thus, the $\mathrm{NH}_{4} \mathrm{Cl}$ value of $\Delta h_{r x n}^{\circ}=176.340 \mathrm{~kJ} / \mathrm{mol}$ (Callanan \& Smith, 1971) was assumed for all amines in this work, except for the EDA salt. Since the EDA salt contains $2 \mathrm{HCl}$ molecules, an $\Delta h_{r x n}^{\circ}=352.680$ was assumed. The required data for the amines investigated are listed in Table 1. The data for ionization constants (pKa) are also listed in Table 1.

\subsection{3 pH calculation}

\subsubsection{Water $\mathrm{pH}$}

In the calculation of water $\mathrm{pH}$, concepts of ionization and equilibrium constants are used. Water has a high polarity and, in liquid phases, it becomes slightly ionized. That ionization can be represented by the following reaction:

$\mathrm{H}_{2} \mathrm{O} \leftrightarrow \mathrm{H}^{+}+\mathrm{OH}^{-}$

Therefore, it is possible to represent the above reaction in terms of its equilibrium constant:

$K_{a, W}=\frac{a_{H^{+}} a_{O H^{-}}}{a_{W}}=\frac{M_{H^{+}} M_{O H^{-}}}{M}$

Where:
$K_{a, W}$ : equilibrium constant of water;

$a_{i}$ : species activity ionic representations;

$M_{i}$ : molal concentrations.

With $K_{a, W}$ it is possible to calculate the ionization constant $\left(p K_{a, W}\right)$ through the relation.

$p K_{a, W}=-\log _{10}\left(K_{a, W}\right)$

In a similar way, the $\mathrm{pH}$ is defined as:

$p H=-\log _{10}\left(a_{H^{+}}\right)$

\subsubsection{2 $\mathrm{pH}$ in condensate vessel conditions}

The $\mathrm{pH}$ in the condensate vessel represents the calculation of the acidity of the condensate, consisting of water, amines, and acidic species. Thus, this $\mathrm{pH}$ can be calculated through the solution of simultaneous acid-base reactions of all species present. To all bases, using $\mathrm{NH}_{3}$ as an example, the following reaction is considered:

$\mathrm{NH}_{3(l)}+\mathrm{H}_{2} \mathrm{O}_{(l)} \leftrightarrow \mathrm{NH}_{4}^{+(a q)}+\mathrm{OH}_{(a q)}^{-}$

And for acids, taking $\mathrm{HCl}$ as an example:

$\mathrm{HCl}_{(l)} \leftrightarrow H_{(a q)}^{+}+\mathrm{Cl}_{(a q)}^{-}$

Each of these reactions presents an associated equilibrium constant. A set of equations involving all acids and bases present in the solution must be solved simultaneously to determine the $\mathrm{H}+$ concentration. Thus, Equation 11 allows $\mathrm{pH}$ calculation. 
Table 2. Assumed specific cost and density of ammonia and amines.

\begin{tabular}{llll}
\hline Amines & $\begin{array}{l}\text { Temperature } \\
\text { Amines }\left({ }^{\circ} \mathrm{C}\right)\end{array}$ & $\rho(\mathrm{kg} / \mathrm{L})$ & US\$/ton \\
\hline $\mathrm{NH}_{3}$ & 20 & $0.900[12]$ & $430[9]$ \\
MOPA & 25 & $0.874[12]$ & $3100[10]$ \\
$\mathrm{MEA}$ & 25 & $1.012[12]$ & $1700[9]$ \\
$\mathrm{NMM}$ & 25 & $0.920[12]$ & $3910[11]$ \\
$\mathrm{TMA}$ & 20 & $0.630[12]$ & $887[11]$ \\
EDA & 25 & $0.899[12]$ & $1730[10]$ \\
PYRID & 25 & $0.978[12]$ & $2400[9]$ \\
\hline [9](ALIBABA.COM 2016), [10](FOCUS TECHNOLOGY CO. 2016), \\
[11](MOLBASE 2016), [12](SIGMA-ALDRICH 2016).
\end{tabular}

Table 3. Required input data for the case studies investigated in this work.

\begin{tabular}{|c|c|c|c|c|c|}
\hline OVHD System & Data & Case 1 & Case 2 & Case 3 & Case 4 \\
\hline & Feed $\left(\mathrm{m}^{3} / \mathrm{h}\right)$ & 1000.00 & 1000.00 & 1000.00 & 1000.00 \\
\hline \multirow[t]{4}{*}{ Feed and Reflux } & Water (\%) & 0.00 & 0.00 & 0.00 & 0.00 \\
\hline & Total Steam (ton/h) & 2.46 & 4.00 & 4.00 & 4.00 \\
\hline & $\operatorname{Reflux}\left(\mathrm{m}^{3} / \mathrm{h}\right)$ & 50.67 & 100.75 & 90.75 & 100.75 \\
\hline & Temperature $\left({ }^{\circ} \mathrm{C}\right)$ & 105.00 & 127.00 & 127.00 & 127.00 \\
\hline \multirow[t]{4}{*}{ Tower Top } & Pressure $\left(\mathrm{kgf} / \mathrm{cm}^{2}\right)$ & 1.90 & 1.10 & 2.72 & 1.10 \\
\hline & Flow (L/h) & 1.00 & 1.00 & 1.00 & 1.00 \\
\hline & Temperature $\left({ }^{\circ} \mathrm{C}\right)$ & 50.00 & 55.00 & 58.80 & 55.00 \\
\hline & Chlorides (ppm) & 122.00 & 47.00 & 11.00 & 47.00 \\
\hline \multirow[t]{4}{*}{ Condensed Vessel } & Ammonia (ppm) & 0.00 & 31.00 & 3.10 & 0.00 \\
\hline & Remaining water (ton/h) & 5.00 & 5.00 & 5.00 & 5.00 \\
\hline & Sulfides (ppm) & 13.00 & 6.00 & 13.00 & 6.00 \\
\hline & Organic acids (ppm) & 23.00 & 15.00 & 5.70 & 15.00 \\
\hline \multirow[t]{4}{*}{ Naphtha } & Flow rate $\left(\mathrm{m}^{3} / \mathrm{h}\right)$ & 16.00 & 8.00 & 10.00 & 8.00 \\
\hline & $\mathrm{SG}\left(\mathrm{kgf} / \mathrm{cm}^{2}\right)$ & 0.76 & 0.69 & 0.69 & 0.69 \\
\hline & $0 \%$ & 29.10 & 25.00 & 25.00 & 25.00 \\
\hline & $10 \%$ & 50.70 & 30.00 & 30.00 & 30.00 \\
\hline \multirow{5}{*}{$\begin{array}{l}\text { Naphtha distillation } \\
\text { curve } \\
\text { (ASTM D86 Method) }\end{array}$} & $30 \%$ & 68.40 & 45.00 & 38.00 & 45.00 \\
\hline & $50 \%$ & 82.00 & 95.00 & 78.70 & 95.00 \\
\hline & $70 \%$ & 92.30 & 125.00 & 107.90 & 125.00 \\
\hline & $90 \%$ & 107.20 & 145.00 & 136.54 & 145.00 \\
\hline & $100 \%$ & 121.10 & 185.00 & 185.00 & 185.00 \\
\hline
\end{tabular}

\subsection{Cost and properties of amines}

For the calculation of the operating costs and properties, assumed amine quotations as listed in Table 2.

All amines listed in Table 2 are used commonly in distillation towers, generally in aqueous solution (Lehrer \& Edmondson, 1993). The TMA is an exception compared to the rest of the amines, since it has a high vapor pressure. This may pose additional difficulties for its practical use (Felsing \& Phililips, 1936).

\section{RESULTS E DISCUSSIONS}

This section presents the optimization results of four different cases. All cases studied present different input data, aiming to cover typical conditions observed in Brazilian refineries. 


\subsection{Case studies}

This work investigates four case studies, with different operating conditions. Required input data for these cases are listed in Table 3. Neutralization is obtained by the addition of amines $\left(\mathrm{NH}_{3}, \mathrm{MOPA}\right.$, MEA, NMM, TMA, EDA, and PYRID) given by their total flow $(\mathrm{L} / \mathrm{h})$. Different optimization results for each case are listed on Tables 4, 5, 6, and 7. These tables provide resulting individual amine flow rates $(\mathrm{L} / \mathrm{h})$ as well as volumetric fractions (\%). The operational cost (US\$/h) is the objective function, given by $\sum_{i=1}^{i} C A_{i} F A_{i}$, where $\left(F A_{i}\right)$ is the total flow of the amine, and $i(\mathrm{~L} / \mathrm{h})$ and $\left(C A_{i}\right)$ are the specific cost (US\$/L).

For each case, different scenarios were investigated. First, two mixture compositions were selected randomly as candidates for operation (indicated as Mixture 1 and Mixture 2 in Tables 47). These mixtures represent the typical trial and error present in the empirical product formulation. With the compositions fixed (volume fractions), only the total flow was optimized to respect operational constraints (dew point, salt point, and $\mathrm{pH})$. Thus, Mixture 1 and Mixture 2 results will always be sub-optimal.

Afterwards, with Mixture 1 and Mixture 2 results set as initial point, the local search method (NM) was used to optimize the conditions, leading to the conditions identified as Optimization $1 \mathrm{NM}$ and Optimization $2 \mathrm{NM}$, respectively. Finally, a global optimization (PSO) was also executed for each case, with results identified as Optimization PSO.

\subsubsection{Case 1}

With the input data of Table 3 for Case 1, the operational parameters and the optimized cost of were calculated, with results listed in Table 4.

Mixtures 1 and 2 represent typical trial and error formulation with a total flow that satisfies operating constraints.

Table 4. Optimization results for Case 1.

\begin{tabular}{|c|c|c|c|c|c|c|c|c|c|}
\hline \multicolumn{4}{|c|}{ Optimization Variables } & \multicolumn{6}{|c|}{ Operational Parameters } \\
\hline & Amines & Flow & $\%$ & Water Flow & Water & Salt & $\mathrm{pH}$ & Cost & Time \\
\hline & & & & & Dew & Formation & & & \\
\hline & & $(\mathrm{L} / \mathrm{h})$ & & $\left(\mathrm{m}^{3} / \mathrm{h}\right)$ & Point $\left({ }^{\circ} \mathrm{C}\right)$ & Point $\left({ }^{\circ} \mathrm{C}\right)$ & OVHD & (US\$/h) & (ms) \\
\hline \multirow{3}{*}{ Mixture 1} & TMA & 0.86 & 50.00 & & & & & & \\
\hline & PYRID & 0.86 & 50.00 & & & & & & \\
\hline & TOTAL & 1.72 & 100.00 & 11.55 & 98.36 & 91.79 & 6.500 & 2.490 & - \\
\hline \multirow{7}{*}{$\begin{array}{l}\text { Optimization } 1 \\
\mathrm{NM}^{*}\end{array}$} & $\mathrm{NH}_{3}$ & 0.07 & 5.46 & & & & & & \\
\hline & MOPA & 0.09 & 6.93 & & & & & & \\
\hline & MEA & 0.05 & 4.34 & & & & & & \\
\hline & TMA & 0.50 & 39.39 & & & & & & \\
\hline & EDA & 0.06 & 4.48 & & & & & & \\
\hline & PYRID & 0.50 & 39.40 & & & & & & \\
\hline & TOTAL & 1.27 & 100.00 & 11.55 & 98.36 & 91.79 & 6.500 & 1.898 & 865 \\
\hline \multirow{5}{*}{ Mixture 2} & $\mathrm{NH}_{3}$ & 0.10 & 5.00 & & & & & & \\
\hline & TMA & 0.76 & 40.00 & & & & & & \\
\hline & PYRID & 0.29 & 15.00 & & & & & & \\
\hline & WATER & 0.76 & 40.00 & & & & & & \\
\hline & TOTAL & 1.91 & 100.00 & 11.55 & 98.36 & 95.35 & 6.500 & 1.140 & - \\
\hline \multirow{6}{*}{$\begin{array}{l}\text { Optimization } 2 \\
\mathrm{NM}^{*}\end{array}$} & $\mathrm{NH}_{3}$ & 0.13 & 14.30 & & & & & & \\
\hline & NMM & 0.04 & 4.80 & & & & & & \\
\hline & TMA & 0.43 & 48.50 & & & & & & \\
\hline & EDA & 0.12 & 13.76 & & & & & & \\
\hline & PYRID & 0.17 & 18.64 & & & & & & \\
\hline & TOTAL & 0.89 & 100.00 & 11.55 & 98.36 & 95.35 & 6.500 & 1.028 & 2117 \\
\hline \multirow{2}{*}{$\begin{array}{l}\text { Optimization } \\
\text { PSO** }\end{array}$} & NMM & 0.88 & 100.00 & & & & & & \\
\hline & TOTAL & 0.88 & 100.00 & 11.55 & 98.36 & 97.52 & 6.500 & 0.341 & 4965 \\
\hline
\end{tabular}

*NM: Nelder-Mead simplex numerical method. **PSO: Particle Swarm Optimization numerical method. 
Table 5. Optimization results for Case 2.

\begin{tabular}{|c|c|c|c|c|c|c|c|c|c|}
\hline \multicolumn{4}{|c|}{ Variables of Optimization } & \multicolumn{6}{|c|}{ Operational Parameters } \\
\hline & Amines & Flow & $\%$ & Water Flow & Water & Salt & $\mathrm{pH}$ & Cost & Time \\
\hline & & & & & Dew & Formation & & & \\
\hline & & $(\mathrm{L} / \mathrm{h})$ & & $\left(\mathrm{m}^{3} / \mathrm{h}\right)$ & Point $\left({ }^{\circ} \mathrm{C}\right)$ & Point $\left({ }^{\circ} \mathrm{C}\right)$ & OVHD & (US\$/h) & (ms) \\
\hline & TMA & 0.50 & 50.00 & & & & & & \\
\hline \multirow[t]{3}{*}{ Mixture 1} & PYRID & 0.50 & 50.00 & & & & & & \\
\hline & TOTAL & 1.00 & 100.00 & 14.20 & 94.30 & 101.11 & 7.710 & 1.453 & - \\
\hline & TMA & 0.50 & 50.00 & & & & & & \\
\hline Optimization 1 & PYRID & 0.50 & 50.00 & & & & & & \\
\hline \multirow[t]{3}{*}{$\mathrm{NM}^{*}$} & TOTAL & 1.00 & 100.00 & 14.20 & 94.30 & 101.11 & 7.710 & 1.453 & 1097 \\
\hline & $\mathrm{NH}_{3}$ & 0.05 & 5.00 & & & & & & \\
\hline & TMA & 0.40 & 40.00 & & & & & & \\
\hline \multirow[t]{4}{*}{ Mixture 2} & PYRID & 0.15 & 15.00 & & & & & & \\
\hline & WATER & 0.60 & 40.00 & & & & & & \\
\hline & TOTAL & 1.20 & 100.00 & 14.20 & 94.30 & 101.62 & 7.630 & 0.595 & - \\
\hline & TMA & 0.40 & 72.73 & & & & & & \\
\hline Optimization 2 & PYRID & 0.15 & 27.27 & & & & & & \\
\hline $\mathrm{NM}^{*}$ & TOTAL & 0.55 & 100.00 & 14.20 & 98.30 & 101.62 & 7.590 & 0.575 & 962 \\
\hline $\begin{array}{l}\text { Optimization } \\
\text { PSO }^{* *}\end{array}$ & TOTAL & 0.00 & 100.00 & 14.20 & 94.31 & 101.12 & 6.610 & 0.000 & 2096 \\
\hline
\end{tabular}

*NM: Nelder-Mead simplex numerical method. **PSO: Particle Swarm Optimization numerical method.

The NM method was able to further reduce the costs, while respecting the operating constraints. The results of optimizations 1 and 2 presented values below those calculated with their initial points. Multiple minima were identified, since different starting points lead to different solutions. A particular characteristic of this case is the absence of ammonia in the condensate vessel, opening the opportunity to the addition of NH3 by the local optimizer. The global search algorithm (PSO) was able to find a much better solution, one with a lower cost. In all optimization results presented in Table 4, the computational times were low. They were below 2000 milliseconds using the NM method, and below 5000 milliseconds using the PSO method. As expected, the PSO method demanded a higher computational time, given its global search nature.

\subsubsection{Case 2}

Results for Case 2 are listed in Table 5. For this case, initial mixtures (Mixture 1 and Mixture 2) were selected so that the salt formation temperature constraint was not satisfied. All the mixtures presented salt formation temperatures higher than the water dew point temperature. The salts precipitate in the solid form in piping and equipment, which can initiate a corrosive process. However, the $\mathrm{pH}$ condition of the condensate vessel was satisfied for all the mixtures. In both NM optimizations, with starting point given either by Mixture 1 or Mixture 2, temperature optimization constraint was not satisfied. These difficulties are due to high concentrations of ammonia ( $31 \mathrm{ppm}$ in Table 3) already present in the condensate vessel prior to the addition of other neutralizers. The local optimizer could not identify this problem and, therefore, could not bypass it. The PSO optimizer was also unable to find a feasible solution, but it suggested, correctly, not to add more amines in this case. This makes it clear that this case has an inherent problem; either $\mathrm{HCl}$ or $\mathrm{NH}_{3}$ concentrations need to be reduced to avoid solid precipitation.

\subsubsection{Case 3}

For Case 3, optimization results are listed in 
Table 6. Optimization results for Case 3.

\begin{tabular}{|c|c|c|c|c|c|c|c|c|c|}
\hline \multicolumn{4}{|c|}{ Variables of Optimization } & \multicolumn{6}{|c|}{ Operational Parameters } \\
\hline & Amines & Flow & $\%$ & Water Flow & Water & Salt & $\mathrm{pH}$ & Cost & Time \\
\hline & & & & & Dew & Formation & & & \\
\hline & & $(\mathrm{L} / \mathrm{h})$ & & $\left(\mathrm{m}^{3} / \mathrm{h}\right)$ & Point $\left({ }^{\circ} \mathrm{C}\right)$ & Point $\left({ }^{\circ} \mathrm{C}\right)$ & OVHD & (US\$/h) & (ms) \\
\hline & $\mathrm{NH}_{3}$ & 0.13 & 10.00 & & & & & & \\
\hline \multirow[t]{6}{*}{ Mixture 1} & PYRID & 0.52 & 40.00 & & & & & & \\
\hline & WATER & 0.65 & 50.00 & & & & & & \\
\hline & TOTAL & 1.29 & 100.00 & 14.13 & 108.33 & 90.17 & 6.500 & 1.260 & - \\
\hline & $\mathrm{NH}_{3}$ & 0.12 & 18.80 & & & & & & \\
\hline & MOPA & 0.01 & 1.45 & & & & & & \\
\hline & NMM & 0.03 & 4.73 & & & & & & \\
\hline Optimization 1 & TMA & 0.05 & 7.20 & & & & & & \\
\hline \multirow[t]{5}{*}{$\mathrm{NM}^{*}$} & EDA & 0.03 & 5.53 & & & & & & \\
\hline & PYRID & 0.41 & 62.30 & & & & & & \\
\hline & TOTAL & 0.65 & 100.00 & 14.13 & 108.33 & 90.17 & 6.500 & 1.210 & 1453 \\
\hline & MOPA & 0.10 & 5.00 & & & & & & \\
\hline & MEA & 0.76 & 40.00 & & & & & & \\
\hline \multirow[t]{5}{*}{ Mixture 2} & NMM & 0.29 & 15.00 & & & & & & \\
\hline & TMA & 0.76 & 40.00 & & & & & & \\
\hline & TOTAL & 1.91 & 100.00 & 14.13 & 108.33 & 99.20 & 8.340 & 0.876 & - \\
\hline & $\mathrm{NH}_{3}$ & 0.06 & 6.40 & & & & & & \\
\hline & MOPA & 0.03 & 3.20 & & & & & & \\
\hline \multirow{4}{*}{$\begin{array}{l}\text { Optimization } 2 \\
\mathrm{NM}^{*}\end{array}$} & NMM & 0.01 & 1.00 & & & & & & \\
\hline & TMA & 0.81 & 86.20 & & & & & & \\
\hline & EDA & 0.03 & 3.20 & & & & & & \\
\hline & TOTAL & 0.94 & 100.00 & 14.13 & 108.33 & 99.20 & 8.288 & 0.637 & 2191 \\
\hline Optimization & $\mathrm{NH}_{3}$ & 0.13 & 100.00 & & & & & & \\
\hline PSO $^{* *}$ & TOTAL & 0.13 & 100.00 & 14.13 & 108.33 & 99.20 & 6.500 & 0.050 & 3854 \\
\hline
\end{tabular}

*NM: Nelder-Mead simplex numerical method. **PSO: Particle Swarm Optimization numerical method.

Table 6. In Case 3, as in Case 1, the initial point mixtures (Mixture 1 and Mixture 2) satisfied operating constraints. In the respective local optimizations, all optimization constraints were met and costs were minimized. Again, the local search method produced different results for different start points. The PSO global method, which does not need an initial estimate, was able to find a much better response, one with a lower cost. Computation times were also low, around $2000 \mathrm{~ms}$ for the local search and $4000 \mathrm{~ms}$ for the global search. Interestingly, for this case, the best solution found was to simply add the correct amount for the cheapest neutralizer $\left(\mathrm{NH}_{3}\right)$. This was possible due to the low Chlorides concentration present (see Table 3).

\subsubsection{Case 4}

The input data for Case 4 is identical to that of Case 2, but without the presence of ammonia. Recalling that Case 2 was found to be infeasible, and possible solutions to make it viable would either reduce chloride or ammonia concentrations. Optimized results for Case 4 are listed on Table 7. 
Table 7. Optimization results for Case 4.

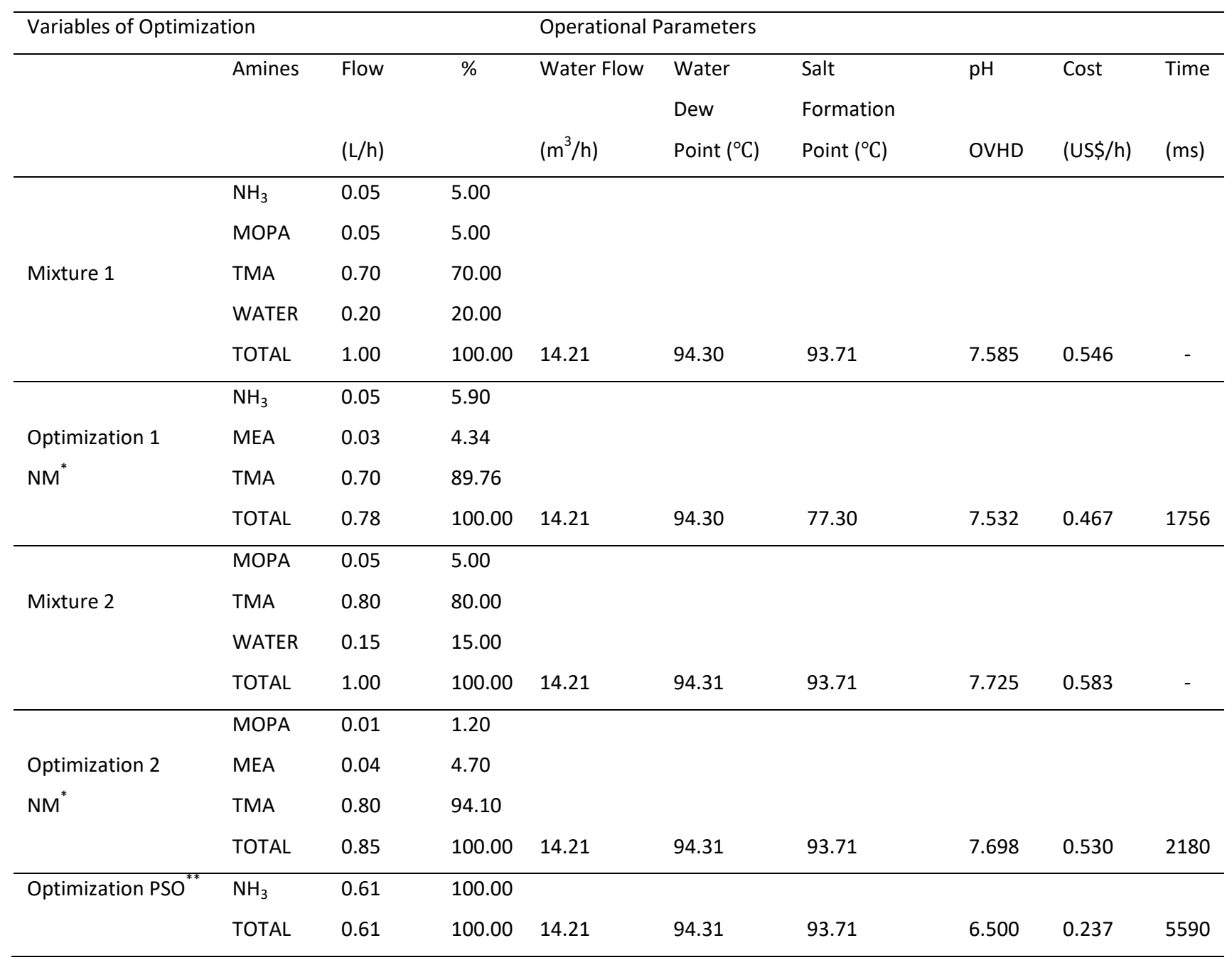

*NM: Nelder-Mead simplex numerical method. **PSO: Particle Swarm Optimization numerical method.

Again, the initial mixtures (Mixture 1 and Mixture 2) represent feasible solutions, respecting the operating constraints. Similar to other cases, the local search method was able to improve initial conditions. Similar to other cases, the PSO method was able to find better (cheaper) solution.

\section{CONCLUSIONS}

In this work, the optimization of amine addition was investigated for four different case studies. Mixtures randomly selected (representing the typical trial and error present in empirical formulations) were compared with optimized ones. The optimizations had to respect $\mathrm{pH}$ as well as salt formation temperature limits. Two numerical optimization methods were implemented: simplex Nelder-Mead (local search) and PSO (global search). Regarding the local method, different optimal values were found for different initial estimatives. When using the global PSO method, a much better solution, one with a lower cost, was found in all cases.

\section{ACKNOWLEDGMENTS}

This work was supported partially by PETROBRAS, under contract no. 0050.0094379.14.9.

\section{REFERENCES}

ALIBABA. Available at: <https://www.alibaba.com/>. Accessed on: 31 August 2016. 
Belusso, A. C.; Silva, G. P. M.; Soares, R. P.; Staudt, P. B. Determinação de pressão e entalpia de sublimação de cloridratos de aminas através da técnica termogravimétrica, 2017, Proceedings of the. IX Congresso Brasileiro de Termodinâmica, Porto Alegre - RS. (in Portuguese)

Branden, V. K.; Fearnside, P.; Murphy, C. J. Amine blend neutralizers for refinary process corrosion. 1999. US Patent 5,965,785.

Brown, K. L.; Chernoff, D.; Keljo, D. J.; Kallen, R. G. Coenzyme B12 model studies. Equilibriums and kinetics of axial ligation of methylaquocobaloxime by primary amines and 4-substituted pyridines. Journal of the American Chemical Sociey, v. 94, p. 6697-6704, 1971. https://doi.org/10.1021/ja00774a022

Callanan, J. E.; Smith, N. O. Sublimation pressures of solid solutions III. $\mathrm{NH} 4 \mathrm{Cl}+\mathrm{NH} 4 \mathrm{Br}$. The Journal of Chemical Thermodynamics. v.3, p. 531538, 1971. https://doi.org/10.1016/S0021$\underline{9614(71) 80036-8}$

Fearnside, P.; Murphy, C. J. Process using amine blends to inhibit chloride corrosion in wet hydrocarbon condensing systems. 1998. US Patent $5,714,664$.

Fearnside, P.; Murphy, C. J. Processo para inibir a corrossão em sistesmas de condensação. 1995. Patente PI 9403883-0 A. (in Portuguese)

Felsing , W. A.; Phililips, B. A. Partial vapor pressures of aqueous methylamine solutions. Journal of the American Chemical Society, v.58, p. 1973-1975, 1936.

https://doi.org/10.1021/ja01301a041

FOCUS TECHNOLOGY CO. Available at: $<$ http://www.made-in-china.com/>. Accessed on: 29 August 2016.

Gutzeit, J. Crude Unit Corrosion Guide a Complete How-To Manual, 2nd Edition. Houston: NACE International, Process Corrosion Consultants - PCC, 2006.
Hall, H. K. Correlation of the base strengths of amines. Journal of the American Chemical Society, v. 79, p. 5441-5444, 1957. https://doi.org/10.1021/ia01577a030

Hamborg, E. S.; Versteeg, G. F. Dissociation constants and thermodynamic properties of amines and alkanolamines from (293 to 353) K. Journal of Chemical and Engineering Data, v. 54, p. 1318-1328, 2009. https://doi.org/10.1021/je800897v

Kennedy, J.; Eberhart, R. Particle swarm optimization, 2005, Australia, IEEE - Proceedings of ICNN'95 - International Conference on Neural Networks. v.4, p. 1942-1948, 1995.

Koretsky, M. D. Engineering and Chemical Thermodynamics, 2nd Edition. USA: Wiley Global Education, 704p, 2012.

Lehrer, S. E.; Edmondson, J. G. Neutralizing amines with low salt precipitation potencial. Patent number 5,211,840, 1993.

McLaughlin, B. D.; Wu, Y-M. Water washing to remove salts. US Patent 5,656,152, 1997.

MOLBASE. Available at: <http://www.molbase.com/>. Accessed on: 23 August 2016..

Nelder, J. A.; Mead, R. A. Simplex method for function minimization. Computer Journal, p. 308313, 1964. https://doi.org/10.1093/comjnl/7.4.308

Neves, D. L. C. Estudo comparativo entre técnicas de controle da corrosão por condensação ácida em sistemas de topo de unidades de destilação de petróleo. 176 f. Tese de Doutorado. Programa de Pós-Graduação em Engenharia Metalúrgica e de Materiais, Universidade Federal do Rio de Janeiro, COPPE, 2009. (in Portuguese)

SIGMA-ALDRICH. Available at: <http://www.sigmaaldrich.com>. Accessed on: 25 August 2016. 